\title{
Coordinating a Supply Chain under O2O Business Model When Facing Multiple Disruptions
}

\author{
Jun Zhang ${ }^{1, a}$, Hong Chen ${ }^{2, b, *}$ \\ ${ }^{1}$ Logistics Engineering and Management Faculty, Kunming Metallurgy College, NO.388 Xuefu Road, \\ Kunming, China \\ ${ }^{2}$ School of Management and Economics, University of Electronic Science and Technology of China, \\ NO.2006 Xiyuan Avenue, Chengdu, China \\ a zjun434@sina.com.cn, ${ }^{\text {b }}$ chenh@uestc.edu.cn \\ *corresponding author
}

Keywords: O2O business model; supply chain; demand disruption; retailer's sales cost disruption; supply chain coordination.

\begin{abstract}
A supply chain under O2O business model, a new kind of supply chain, is studied in this paper, in which the supply chain is consisted of one supplier (she) and multiple O2O retailers. The supplier finds that demand disruption and retailer's sales cost disruption takes place after her production plan is formulated. How to optimize the total supply chain profit in the centralized and the decentralized decisions is analyzed by using Stackelberg game, which is also a new problem compared with the previous studies. The results obtained are as follows. In the centralized decision, the supplier needs to adjust the channel price if the disruptions satisfy a given condition. If the disruptions satisfy other conditions, the supplier needs to change both the channel retail price and the production quantity. In the decentralized decision, an adjusted revenue-sharing contract, a new supply contract, can coordinate the disrupted supply chain.
\end{abstract}

\section{Introduction}

The development of e-commerce grows rapidly around the world in recent years. E-commerce profoundly changes customers' consumption habit, which also has a great impact on the production and operation of traditional manufacturers and retailers. In this setting, O2O (Online to Offline/Offline to Online) business model, a new business model, is developed by some high-tech companies. They suggest that companies in the future should integrate online business with offline business. With the spread of information technology, O2O business model becomes localized and integrates with mobile devices at the end of 2013, which means that a new era of $\mathrm{O} 2 \mathrm{O}$ business model begins. For example, Tmall, an e-retailer affiliated to Alibaba, begins to cooperate with Intime Department Store in 2013. Many e-retailers in China become O2O retailers when they sell products online and improve customers' shopping experience in their online and offline channels. E-commerce companies are $\mathrm{O} 2 \mathrm{O}$ retailers, which include Taobao, Tmall, Amazon, Dangdang and Jingdong Shopping Center. They are exactly the objects we study in this paper.

However, disruptions can influence supply chain operation, which include public health events, natural disasters and machine faults. An initially-coordinated supply chain cannot be coordinated because of disruptions, and whether supply chain members can survive or not can be influenced by disruptions. For example, the spread of plague caused by H7N9 in China makes the demand of chicken for food decrease dramatically. The spread of foot-and-mouth disease makes the demand for beef in Europe decrease dramatically, which influences the operation of beef supply chain in Europe. With the development of e-commerce, shopping online is widely spread throughout China. According to some statistics, the total sales volume in Tmall is about 120.7 billion RMB on 11th November 2016, which greatly influences the operation of its online and offline supply chain system. The e-retailers need to preorder a large number of products in order to meet the coming demand, and the logistics system is greatly affected by activities such as storing, transporting and 
distributing etc.

As it can be seen above, supply chain operation, supply chain members' decisions and even supply chain profit can be affected by disruptions. The influence is so profound that it is important to discuss how to coordinate supply chain when disruptions happen [1]. This problem has been emphasized by scholars and companies worldwide.

\section{Literature Review}

Current research related to $\mathrm{O} 2 \mathrm{O}$ business model focuses on recommendation system and how to improve e-commerce service. Tsai et al. find that retailers implementing $\mathrm{O} 2 \mathrm{O}$ business model can better understand their customers [2]. Chen et al. and Hsieh et al. believe that improvements in recommendation system can improve online service and attract more online customers [3, 4]. Hong examines the role of $\mathrm{O} 2 \mathrm{O}$ business model in the marketing of local fresh produce [5]. The O2O business model in China is analyzed by Zhao [6] and Zhao [7], respectively.

Studies closely related to this paper are called as disruption management. Clausen et al. firstly put forward disruption management [8]. How to coordinate supply chain with different disruptions is discussed by Qi et al. [9], Xu et al. [10, 15] and Huang et al. [11]. Lei et al. examine how to coordinate a one-supplier-one-retailer supply chain under asymmetric information with a linear contract [12]. Zhang et al. investigate different two-echelon supply chains under O2O business model, respectively $[14,16]$.

Compared with previous studies, there are some differences in this paper. Firstly, a one-suppliermultiple-O2O-retailers supply chain under $\mathrm{O} 2 \mathrm{O}$ business model, a new kind of supply chain, is established. Secondly, although the impact of the demand disruption on supply chain coordination is analyzed in this paper, the problem discussed is different from Zhang et al. Thirdly, this paper examines the role of the revenue-sharing contract in how to coordinate a disrupted supply chain system, which is also different from Xu et al., Qi et al., Huang et al. and Zhang et al.

\section{Basic Model}

A supply chain system consisted of one supplier (she) and multiple O2O retailers is studied in this paper. The supplier is the Stackelberg leader, and she controls the wholesale price and the revenue allocation ratio $\phi$. Those $\mathrm{O} 2 \mathrm{O}$ retailers are the Stackelberg followers. The transaction between the supplier and those retailers is realized under symmetric information. The number of O2O retailers is $N$. The supplier sells a kind of short-life-cycle product to each retailer according to her market forecast. Each retailer sells the product to consumers by using $\mathrm{O} 2 \mathrm{O}$ e-commerce website, and customers evaluate the online shopping experience at the website after they receive the product offline. Each retailer outsources his product distribution to a third-party logistics company. Those $\mathrm{O} 2 \mathrm{O}$ retailers decide whether or not to sell the product according to the revenue-sharing contract the supplier provides.

Suppose that the retail price in each segmented market is $p_{i}$ and the demand function that the $i$-th $\mathrm{O} 2 \mathrm{O}$ retailer faces in each segmented market is $d_{i}=D_{i} p_{i}^{-2 k_{i}}(i=1,2, \ldots, N)$. The potential market scale in the $i$-th market is $D_{i}$ and the supplier's unit production cost is $c_{s}$. Each retailer outsources his distribution. Each retailer's unit sales cost is $c_{r i}$ which includes the unit cost of using O2O ecommerce website and the unit cost of distributing his product. The retail price in the $i$-th market is $p_{i}$ and the price sensitivity coefficient in the $i$-th market is $k_{i}\left(k_{i}>0\right)$. The realized demand in the $i$ th market is $Q_{i}=D_{i} p_{i}^{-2 k_{i}}$ and the retail price in the $i$-th market is $p_{i}=\left(\frac{D_{i}}{Q_{i}}\right)^{\frac{1}{2 k_{i}}}$. The total profit of the supply chain system is

$$
\bar{f}^{T}\left(Q_{i}\right)=\sum_{i=1}^{N} Q_{i}\left[\left(\frac{D_{i}}{Q_{i}}\right)^{\frac{1}{2 k_{i}}}-c_{s}-c_{r i}\right]
$$


From the first-order optimality condition, we obtain that the optimal retail price in each segmented market is $\bar{p}_{i}=\frac{2 k_{i}\left(c_{s}+c_{r i}\right)}{2 k_{i}-1}$, the optimal production quantity in each segmented market is $\overline{Q_{i}}=D_{i}\left[\frac{2 k_{i}-1}{2 k_{i}\left(c_{s}+c_{r i}\right)}\right]^{2 k_{i}}$, and the optimal supply chain profit is $\bar{f}_{\max }^{T}\left(\overline{Q_{i}}\right)=\sum_{i=1}^{N} \frac{D_{i}\left(c_{s}+c_{r i}\right)}{2 k_{i}-1}\left[\frac{2 k_{i}-1}{2 k_{i}\left(c_{s}+c_{r i}\right)}\right]^{2 k_{i}}$.

Lemma 1. If $f_{s}\left(\overline{Q_{i}}\right)=(1-\phi) \cdot \bar{f}_{\max }^{T}\left(\overline{Q_{i}}\right)$ with $0<\phi<1$ or $f_{r}\left(\overline{Q_{i}}\right)=\phi \cdot \bar{f}_{\max }^{T}\left(\overline{Q_{i}}\right)$ with $0<\phi<1$, the supply chain system consisted of one supplier and $N$ O2O retailers can be coordinated under the revenue-sharing contract, where the wholesale price is $W_{i}=\phi\left(c_{s}-\frac{1-\phi}{\phi} c_{r i}\right)(0<\phi<1)$. The optimal total profit of the supplier is $f_{s}\left(Q_{i}\right)$ and the optimal total profit of the $N$ O2O retailers is $f_{r}\left(Q_{i}\right)$.

PROOF. When $W_{i}=\phi\left(c_{s}-\frac{1-\phi}{\phi} c_{r i}\right) \quad(0<\phi<1)$, the supplier's profit function under the revenuesharing contract are shown below, where $f_{s i}\left(\overline{Q_{i}}\right)$ is the supplier's optimal profit from the $i$-th $\mathrm{O} 2 \mathrm{O}$ retailer.

$$
f_{s}\left(\overline{Q_{i}}\right)=\sum_{i=1}^{N} f_{s i}\left(\overline{Q_{i}}\right)=\sum_{i=1}^{N}(1-\phi) \bar{p}_{i} \overline{Q_{i}}+\sum_{i=1}^{N}\left(W_{i}-c_{s}\right) \overline{Q_{i}}=\sum_{i=1}^{N}(1-\phi)\left(\bar{p}_{i}-c_{s}-c_{r i}\right) \overline{Q_{i}}=(1-\phi) \bar{f}_{\max }^{T}\left(\overline{Q_{i}}\right)
$$

The other part of the lemma can be proofed by using the similar method. Thus, the revenuesharing contract can coordinate the supply chain system.

\section{Centralized Decision Making in the O2O Supply Chain with Multiple Disruptions}

The supplier finds that both the disruption of the potential market scale in each segmented market and the sales cost disruption of every $\mathrm{O} 2 \mathrm{O}$ retailer happen in the supply chain system after her production plan is formulated. The disruptions are captured by the terms of $\Delta D_{i}$ and $\Delta c_{r i}$, respectively, if and only if $D_{i}+\Delta D_{i}>0$ and $c_{r i}+\Delta c_{r i}>0$, where the disruption of the market scale is $\Delta D_{i}$ and the $i$-th retailer's sales cost disruption is $\Delta c_{r i}$. It ensures that they are practical in the real world. The discussion followed is based on those above conditions.

After the disruptions occur, the demand function in each segmented market is $d_{i}=\left(D_{i}+\Delta D_{i}\right) p_{i}^{-2 k_{i}}$. The corresponding market scale is $Q_{i}=\left(D_{i}+\Delta D_{i}\right) p_{i}^{-2 k_{i}}$ and the retail price is $p_{i}=\left(\frac{D_{i}+\Delta D_{i}}{Q_{i}}\right)^{\frac{1}{2 k_{i}}} \cdot b_{1}\left(b_{1}>0\right)$ is the extra increased unit cost due to increasing the supplier's production quantity and $b_{2}\left(b_{2}>0\right)$ is the extra unit disposal cost due to selling the remained products of the supplier in the secondary market at the price lower than the supplier's marginal production cost. $(x)^{+}=\max \{0, x\}$. To simplify the discussion followed, we put forward the following assumption. The impact of the disruptions on each segmented market every $\mathrm{O} 2 \mathrm{O}$ retailer faces is consistent, which means that each segmented market reacts consistently to the disruptions. That is to say, if any given segmented market scale increases, then every segmented market scale and the total market scale increase. If any given segmented market size decreases, then every segmented market size and the overall market size decrease. Thus, the corresponding total supply chain profit function is written as

$$
f^{T}\left(Q_{i}\right)=\sum_{i=1}^{N} Q_{i}\left[\left(\frac{D_{i}+\Delta D_{i}}{Q_{i}}\right)^{\frac{1}{2 k_{i}}}-c_{s}-c_{r i}-\Delta c_{r i}\right]-b_{1}\left(\sum_{i=1}^{N} Q_{i}-\sum_{i=1}^{N} \bar{Q}_{i}\right)^{+}-b_{2}\left(\sum_{i=1}^{N} \bar{Q}_{i}-\sum_{i=1}^{N} Q_{i}\right)^{+}
$$

To further investigate the impact of the disruptions mentioned above on the initial production plan, we put forward Lemma 2 below.

Lemma 2. If both the market scale disruption and the retailer's sales cost disruption occur, we assume that $Q_{i}^{*}$ is the optimal production quantity which maximizes the supply chain profit function shown in Equation (2). The following results hold: if $\Delta D_{i}>D_{i}\left[\left(1+\frac{\Delta c_{r i}}{c_{s}+c_{r i}}\right)^{2 k_{i}}-1\right]$, then $Q_{i}^{*} \geq \overline{Q_{i}}$; if $\Delta D_{i}<D_{i}\left[\left(1+\frac{\Delta c_{r i}}{c_{s}+c_{r i}}\right)^{2 k_{i}}-1\right]$, then $Q_{i}^{*} \leq \overline{Q_{i}}$. 
According to Lemma 2, if $\Delta D_{i}>D_{i}\left[\left(1+\frac{\Delta c_{r i}}{c_{s}+c_{r i}}\right)^{2 k_{i}}-1\right]$, then $Q_{i}^{*} \geq \overline{Q_{i}}$. Thus, optimizing the total supply chain profit function $f^{T}\left(Q_{i}\right)$ is equal to optimize the strictly concave function

$$
f_{1}^{T}\left(Q_{i}\right)=\sum_{i=1}^{N} Q_{i}\left[\left(\frac{D_{i}+\Delta D_{i}}{Q_{i}}\right)^{\frac{1}{k_{i}}}-c_{s}-c_{r i}-\Delta c_{r i}\right]-b_{1}\left(\sum_{i=1}^{N} Q_{i}-\sum_{i=1}^{N} \overline{Q_{i}}\right)
$$

subject to $Q_{i} \geq \overline{Q_{i}}$.

If $\Delta D_{i}<D_{i}\left[\left(1+\frac{\Delta c_{r i}}{c_{s}+c_{r i}}\right)^{2 k_{i}}-1\right]$, then $Q_{i}^{*} \leq \overline{Q_{i}}$. Thus, optimizing the total supply chain profit function $f^{T}\left(Q_{i}\right)$ is equal to optimize the strictly concave function

$$
f_{2}^{T}\left(Q_{i}\right)=\sum_{i=1}^{N} Q_{i}\left[\left(\frac{D_{i}+\Delta D_{i}}{Q_{i}}\right)^{\frac{1}{k_{i}}}-c_{s}-c_{r i}-\Delta c_{r i}\right]-b_{2}\left(\sum_{i=1}^{N} \overline{Q_{i}}-\sum_{i=1}^{N} Q_{i}\right)
$$

subject to $Q_{i} \leq \overline{Q_{i}}$.

By solving the two problems with the optimization theory, Theorem 1 is obtained which illustrates the optimal decisions in the centralized $\mathrm{O} 2 \mathrm{O}$ supply chain system when the demand disruption and the retailer's sales cost disruption happen.

Theorem 1. When both the market scale and each $\mathrm{O} 2 \mathrm{O}$ retailer's sales cost in each segmented market change and the demand function in each segmented market is $d_{i}=\left(D_{i}+\Delta D_{i}\right) p_{i}^{-2 k_{i}}$, the supplier, the decision-maker in the centralized O2O supply chain system, needs to change the retail price and the production quantity in order to maximize the total supply chain profit. According to different disruptions, the optimal retail price $p_{i}{ }^{*}$ in each segmented market and the optimal production quantity $Q_{i}^{*}$ in each segmented market are shown as follows:

$$
\begin{aligned}
& p_{i}^{*}= \begin{cases}\bar{p}_{i}+\frac{2 k_{i}\left(\Delta c_{r i}+b_{1}\right)}{2 k_{i}-1}, & \text { if } \Delta D_{i}>D_{i}\left[\left(1+\frac{\Delta c_{r i}+b_{1}}{c_{s}+c_{r i}}\right)^{2 k_{i}}-1\right] \\
\bar{p}_{i}\left(1+\frac{\Delta D_{i}}{D_{i}}\right)^{\frac{1}{2 k_{i}}}, & \text { if } D_{i}\left[\left(1+\frac{\Delta c_{r i}-b_{2}}{c_{s}+c_{r i}}\right)^{2 k_{i}}-1\right] \leq \Delta D_{i} \leq D_{i}\left[\left(1+\frac{\Delta c_{r i}+b_{1}}{c_{s}+c_{r i}}\right)^{2 k_{i}}-1\right] \\
\bar{p}_{i}+\frac{2 k_{i}\left(\Delta c_{r i}-b_{2}\right)}{2 k_{i}-1}, & \text { if } \Delta D_{i}<D_{i}\left[\left(1+\frac{\Delta c_{r i}-b_{2}}{c_{s}+c_{r i}}\right)^{2 k_{i}}-1\right] .\end{cases}
\end{aligned}
$$

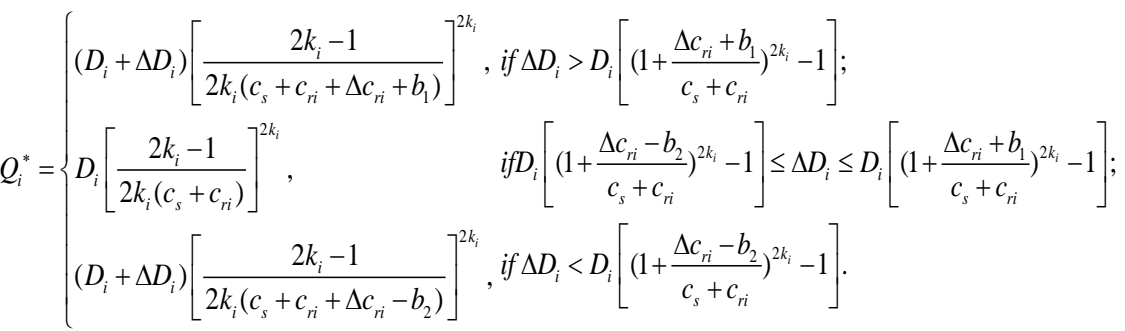

Theorem 1 shows the following results. When both the market scale and the retailer's sales cost in each segmented market change, there exists robustness in the supplier's original production plan. When $\left(\Delta D_{i}, \Delta c_{r i}\right)$ is in a particular interval, the supplier does not need to change the initial production quantity in each segmented market, but she needs to change the retail price in each segmented market in order to compensate for the extra cost derived from the disruptions. The retail price in each segmented market is only influenced by the market scale disruption in each segmented market and is not correlated with each retailer's sales cost disruption. If $\left(\Delta D_{i}, \Delta c_{r i}\right)$ exceeds the interval, the supplier needs to change both her original production quantity and the corresponding retail price in each segmented market according to the disruption of both the market scale and each retailer's sales cost. It is also shown that the initial revenue-sharing contract in this section cannot coordinate the supply chain when the disruptions happen and we must redesign a new supply contract in order to coordinate the supply chain system. 


\section{Coordinating the Decentralized O2O Supply Chain with the Disruptions}

In the centralized decision, when the market scale in each segmented market and the retailer's sales cost change simultaneously, the optimal strategy for the $i$-th $\mathrm{O} 2 \mathrm{O}$ retailer is to choose the retail price $p_{i}^{*}$ and the procurement quantity $Q_{i}^{*}$. In the decentralized decision, if the supply chain members sign an appropriate contract which also makes each $\mathrm{O} 2 \mathrm{O}$ retailer choose $p_{i}^{*}$ and $Q_{i}^{*}$, then the decentralized supply chain achieves the optimal supply capacity which is equal to that in the centralized supply chain system. This means that the supply chain is coordinated in that decision. The revenue-sharing contract is used to coordinate the decentralized supply chain system.

Let $R\left(Q_{i}\right)=b_{1}\left(Q_{i}-\overline{Q_{i}}\right)^{+}+b_{2}\left(\overline{Q_{i}}-Q_{i}\right)^{+}$. Given a revenue allocation ratio $\phi(0<\phi<1)$, the supplier provides O2O retailer $i(i=1, \cdots, N)$ with an improved revenue-sharing contract in which the wholesale price for each O2O retailer is $W_{i}\left(Q_{i}\right)=\phi\left[c_{s}-\frac{1-\phi}{\phi}\left(c_{r i}+\Delta c_{r i}\right)+\frac{R\left(Q_{i}\right)}{Q_{i}}\right]$.

Theorem 2. In the decentralized $\mathrm{O} 2 \mathrm{O}$ supply chain system, if both the market scale and each O2O retailer's sales cost in each segmented market change, the improved revenue-sharing contract in this section can coordinate the supply chain system. The optimal total supply chain profit can be allocated between the supplier and the $N$ O2O retailers in any ratio at the same time.

PROOF. Given a revenue allocation ratio $\phi(0<\phi<1)$, the supplier's total profit function under the revenue-sharing contract is shown below.

$$
\begin{aligned}
f_{s}\left(Q_{i}^{*}\right) & =\sum_{i=1}^{N} f_{s i}\left(Q_{i}^{*}\right)=\sum_{i=1}^{N}\left[(1-\phi) p_{i}^{*} Q_{i}^{*}+W_{i}\left(Q_{i}^{*}\right) Q_{i}^{*}-c_{s} Q_{i}^{*}\right]-b_{1}\left(\sum_{i=1}^{N} Q_{i}^{*}-\sum_{i=1}^{N} \overline{Q_{i}}\right)^{+}-b_{2}\left(\sum_{i=1}^{N} \overline{Q_{i}}-\sum_{i=1}^{N} Q_{i}^{*}\right)^{+} \\
& =\sum_{i=1}^{N}\left[(1-\phi) p_{i}^{*} Q_{i}^{*}+\phi\left(c_{s}-\frac{1-\phi}{\phi}\left(c_{r i}+\Delta c_{r i}\right)+\frac{R\left(Q_{i}^{*}\right)}{Q_{i}^{*}}\right) Q_{i}^{*}-c_{s} Q_{i}^{*}-b_{1}\left(Q_{i}^{*}-\overline{Q_{i}}\right)^{+}-b_{2}\left(\overline{Q_{i}}-Q_{i}^{*}\right)^{+}\right] \\
& =\sum_{i=1}^{N}\left[(1-\phi) p_{i}^{*} Q_{i}^{*}-(1-\phi)\left(c_{s}-c_{r i}-\Delta c_{r i}\right) Q_{i}^{*}-(1-\phi) \cdot R\left(Q_{i}\right)\right]=(1-\phi) \sum_{i=1}^{N}\left[\left(p_{i}^{*}-c_{s}-c_{r i}-\Delta c_{r i}\right) Q_{i}^{*}-R\left(Q_{i}^{*}\right)\right]=(1-\phi) f^{T}\left(Q_{i}^{*}\right)
\end{aligned}
$$

Thus, the supply chain is coordinated and the optimal total channel profit can be allocated among those supply chain members in any allocation ratio by changing the parameter $\phi$. This means that the improved revenue-sharing contract can coordinate the decentralized $\mathrm{O} 2 \mathrm{O}$ supply chain system.

Furthermore, if $\Delta D_{i}=0$ and $\Delta c_{r i}=0$, then $b_{1}=b_{2}=0$. The total supply chain profit function in this scenario is $f^{T}\left(Q_{i}\right)=\bar{f}^{T}\left(Q_{i}\right)$ and the wholesale price is $W_{i}\left(Q_{i}\right)=W_{i}$, which means that the improved revenue-sharing contract can coordinate the supply chain system when the disruptions do not take place. In other words, there exists anti-disruption ability in the improved revenue-sharing contract.

\section{Conclusions}

This paper studies how to coordinate one-supplier-multiple-O2O-retailers supply chain both in the centralized decision and in the decentralized decision when multiple disruptions happen. In the centralized decision, the supplier needs to increase the production quantities in order to meet the increased market demand when the disruption of the market scale and that of the $\mathrm{O} 2 \mathrm{O}$ retailer's sales cost in each segmented market satisfy a given condition. The supplier needs to decrease the production quantities in order to meet the shrunk market demand when the two disruptions satisfy other conditions. There exists robustness in the initial production quantity when making the centralized decision. In other words, when the two disruptions satisfy a given condition, the supplier does not need to change the initial production quantity and she only needs to change the corresponding retail price in order to compensate for the disposal cost derived from the disruptions. Furthermore, she needs to change both the production quantity and the retail price in each segmented market if the disruptions are not in the particular interval. An adjusted revenue-sharing contract is used to coordinate the decentralized $\mathrm{O} 2 \mathrm{O}$ supply chain, which means that the contract can maximize the total profit of the supply chain system discussed in this paper. 


\section{Acknowledgements}

The research was sponsored by National Natural Science Foundation of China (71472026) and Research Fund of Kunming Metallurgy College (14B005).

\section{References}

[1] Jeuland A., Shugan, S. (1983) Managing channel profits. Marketing Science, 2, 239-272.

[2] Tsai, T. M., Yang, P. C., Wang, W. N. (2013) Pilot study toward realizing social effect in O2O commerce services. Social Informatics, 1, 268-273.

[3] Chen, Y. C., Hsieh, H. C., Lin, H. C. (2013) Improved precision recommendation scheme by BPNN algorithm in O2O commerce. IEEE 10th International Conference on e-Business Engineering, 1, 324-328.

[4] Hsieh, H. C., Chen, Y. C., Lin, H. C. (2014) More precise: stores recommendation under O2O commerce. International Journal of Computing and Digital Systems, 3, 91-99.

[5] Hong Wenchang. (2013) Quanzhou agricultural e-commerce platform based on O2O modes. International Workshop on Computer Science in Sports, 1, 173-176.

[6] Zhao, Jun, Wang, Mengyao. (2014a) Investigation and analysis of the Shenyang local O2O business model. International Conference on Mechatronics, Electronic, Industrial and Control Engineering, 1, 1682-1685.

[7] Zhao, Shouxiang, Zhang, Xuewei. (2014b) Research on the development of traditional retail trends based on O2O- Wanda Group as an example. International Conference of the Academy of International Business, 1, 315-320.

[8] Clausen, J., Hansen, J., Larsen, J., et al. (2001) Disruption management. OR/MS Today, 28, 4043.

[9] Qi, Xiangtong, Bard, Jonathan F., Yu, Gang. (2004) Supply chain coordination with demand disruptions. Omega, 32, 301-312.

[10]Xu, M., Qi, X., Yu, G., et al. (2006) Coordinating dyadic supply chains when production costs are disrupted. IIE Transactions, 38, 765-775.

[11]Huang, Chongchao, Yu, Gang, Wang, Song, et al. (2006) Disruption management for supply chain coordination with exponential demand function. Acta Mathematica Scientia, 26, 655-669.

[12]Lei, Dong, Li, Jianbin, Liu, Zhixue. (2012) Supply chain contracts under demand and cost disruptions with asymmetric information. International Journal of Production Economics, 139, 116126.

[13] Cachon, G.P., Larivere, M.A. (2005) Supply chain coordination with revenue sharing contracts: strengths and limitations. Management Science, 51, 30-44.

[14]Zhang, Jun, Chen, Hong, et al. (2015) How to coordinate supply chain under O2O business model when demand deviation happens. Management Science and Engineering, 9, 24-28.

[15] Xu, M., Qi, X., Yu, G. (2003) The demand disruption management problem for a supply chain system with nonlinear demand function. Journal of Systems Science and Systems Engineering, 12, 82-97.

[16] Zhang, Jun, Chen, Hong, Zhang, Wuyi. (2016) How to coordinate supply chain under O2O business model when demand deviation and retailer's sales cost deviation happen. 2016 13th International Conference on Service Systems and Service Management, 1, 157-161. 